\title{
PANCREATITIS LEVE: RELACIÓN ENTRE PCR (PROTEÍNA C REACTIVA) Y EL INICIO DE VÍA ORAL
}

\section{HOSPITAL DE SAN JOSÉ, ENERO 2002 - ENERO 2007}

\author{
Guillermo Aldana D. MD*, Carolina Díaz R. MD**
}

\begin{abstract}
Resumen
Estudio observacional descriptivo de cohorte histórica que busca la relación de la PCR (proteína C reactiva) con el inicio de la vía oral en pacientes con pancreatitis aguda leve que ingresaron al Hospital de San José de Bogotá DC entre enero 2002 y enero 2007. Se analiza la epidemiología y se compara con publicaciones internacionales. Se revisaron 247 historias clínicas de las cuales cumplieron los criterios de inclusión 117. En ningún caso se suspendió la vía oral una vez reiniciada, notando disminución del valor de la PCR con relación al inicial. Fue mayor el porcentaje de pancreatitis severa $(34 \%)$ en nuestra institución mientras que el resto de los valores fueron similares a los reportados en la literatura. La cifra promedio de la PCR al inicio de la vía oral fue de $4.5 \mathrm{mg} / \mathrm{dl}$ (DE 5.5), cifra que podría utilizarse en futuros estudios prospectivos.
\end{abstract}

Palabras clave: PCR, pancreatitis aguda leve, inicio vía oral.

Abreviaturas: PCR, proteína $\mathrm{C}$ reactiva; VO, vía oral.

\section{MILD PANCREATITIS: RELATION BETWEEN CRP (C-REACTIVE PROTEIN) LEVELS AND RESUMING ORAL NUTRITION}

HOSPITAL DE SAN JOSÉ, JANUARY 2002 - JANUARY 2007

\begin{abstract}
An observational historical cohort study was conducted to explore the relation between CRP (C-reactive protein) values and resuming oral intake in patients with acute mild pancreatitis admitted to Hospital de San José Bogotá DC between January 2002 and January 2007. An epidemiologic analysis and comparison with international publications was conducted. Out of 247 clinical records reviewed 117 met inclusion criteria. Oral feeding did not have to be suspended in any patient once reinitiated and a decline in CRP levels was observed as compared with initial values. The percentage of severe pancreatitis $(\mathbf{3 4 \%})$ was higher in our institution while the rest of values were similar to those reported in literature. The mean value of CRP after resuming oral nutrition was $4.5 \mathrm{mg} / \mathrm{dl}$ (SD 5.5), a figure which may be used in future prospective studies.
\end{abstract}

Key words: CRP, acute mild pancreatitis, initiating oral intake.

Fecha recibido: agosto 3 de 2010 - Fecha aceptado: septiembre 13 de 2010

* Cirujano general y de trasplantes. Jefe de los Servicios de Cirugía General y de Trasplantes, Hospital de San José de Bogotá. Profesor
Asistente Fundación Universitaria de Ciencias de la Salud. Bogotá DC. Colombia.

** Residente IV de Cirugía General. Fundación Universitaria de Ciencias de la Salud. Hospital de San José, Bogotá DC. Colombia. 


\section{Introducción}

La pancreatitis aguda es una patología compleja y controversial tanto en su diagnóstico como en su manejo, ${ }^{1}$ con frecuente presentación en los centros de alta complejidad en cirugía general y gastroenterología y que puede tener una alta morbilidad y mortalidad según sea su presentación. ${ }^{2}$

En el manejo general de esta entidad es de gran importancia establecer su etiología y severidad, que son los factores determinantes de los estudios y tratamientos a seguir y que además nos dan luces sobre el pronóstico y posible desenlace. ${ }^{2}$ Para establecer la severidad y tipo de pancreatitis se cuenta en la literatura con varias escalas, entreellas Ranson, APACHE II, Glasgow y otras. En nuestra institución se utiliza APACHE II porque consideramos que es práctica, fácil de aplicar y no sólo clasifica la severidad sino que da una visión global del estado general del paciente. ${ }^{1,3}$

Una vez aclarada la severidad y etiología se determina el tratamiento, que incluye reanimación con líquidos endovenosos, analgesia, reposo intestinal y vigilancia estrecha de la evolución, observando la presencia de signos y síntomas que puedan alarmar sobre aumento en la severidad, compromiso de algúnórgano o sistema y complicaciones para el tratamiento oportuno. ${ }^{2,4}$ Por otro lado, en caso de una evolución favorable surge la pregunta objeto de este trabajo, ¿en qué momento iniciar nutrición por vía oral ?2.5.6 Hay estudios que señalan que un inicio precoz podría aumentar tanto la morbilidad como la mortalidad. ${ }^{2,7}$

Como se mencionó antes, entre las múltiples controversias respecto al tratamiento está determinar el momento oportuno para el inicio de la VO. ${ }^{2,5,6}$ Como parte del manejo propuesto es reposo intestinal ${ }^{7-10}$ se han incluido varias estrategias entre las que se encuentran seguimiento con amilasa o resolución de signos y síntomas como ausencia de dolor o íleo ${ }^{8-13}$ e incluso se han sugerido algunas dietas para el inicio de la VO. ${ }^{3,7,14} \mathrm{En}$ nuestra institución utilizamos la disminución del valor de la PCR, pero no contamos con un estudio objetivo. Esto originó la idea de realizar este trabajo en dos fases, una inicial para describir el comportamiento de la enfermedad en esta institución y buscar el valor pro- medio de la PCR con que se inicia la VO y otro experimental que determine la utilidad de la PCR en el inicio de la VO en pancreatitis leve.

\section{Método}

Estudio observacional descriptivo tipo cohorte histórica. Se utilizó la base de datos de la sección de estadística del Hospital de San José buscando las historias clínicas registradas con los códigos CIE 10 K85x, K860 y K861, en el período comprendido entre enero 2002 y enero 2007. En total se revisaron 247 historias.

Criterios de inclusión: pacientes con diagnóstico de pancreatitis dado por amilasa mayor de $600 \mathrm{mg} / \mathrm{dl}$ o por TAC abdominal, severidad leve determinada por la escala APACHE II con un valor menor de 8, rango de edad entre 16 y 70 años y a quienes se les realizó medición de la PCR. Criterios de exclusión: aquellos con antecedentes de cirugía gástrica reciente a neoplasias de páncreas o del tracto gastrointestinal y los remitidos de otrainstitución.

Una vez confirmada la elegibilidad de la historia clínica se indagaron las variables: edad, género, tipo de pancreatitis (aguda o crónica), grado de APACHE II y cifra de la PCR al ingreso y al inicio de la VO, comorbilidades, tiempo de ayuno en horas desde el ingreso al servicio hasta el inicio de VO, horas de evolución del dolor desde el comienzo de los síntomas hasta llegar al servicio de cirugía general, si suspendió la VO una vez reiniciada, así como la causa y la fecha, complicaciones, mortalidad hasta el egreso del hospital, días de hospitalización y requerimiento de nutrición enteral por sonda. Como se trató de un estudio basado en revisión de historias clínicas no existieron riesgos para los pacientes. Se garantiza total privacidad en el manejo de los datos y que su uso será sólo para fines académicos. Se realizó un análisis estadístico con Stata 10.

\section{Resultados}

Total 117 pacientes; 60 historias con diagnóstico de pancreatitis severa, 43 con datos incompletos y 27 no se 
encontraron en los archivos para un total de 247 historias. La distribución según género fue $63,3 \%$ mujeres y $36,7 \%$ hombres con edad media de 40.3 años (DE 13.4). La distribución según rangos de edad mostró un pico de $30 \%$ en la tercera década (Tabla 1). Según la etiología fue biliar en $56,4 \%$, alcohólica $10,3 \%$ y otras $33,3 \%$ (28 idiopáticas, ocho poscolangiopancreatografía retrógrada, dos medicamentosas, una viral y otra por obstrucción por áscaris) (Tabla 1). En cuanto al tipo de pancreatitis fue aguda en $88 \%$ y crónica $12 \%$ (Tabla 1). La relación de etiología y género fue biliar más frecuente en mujeres con una marcada diferencia, la alcohólica en hombres y otras en mujeres (Tabla 2).

En la puntuación de APACHE II al ingreso, 5 fue el valor más común con 20,6\% (Tabla 1). En la relación entre el valor de APACHE II y de la PCR al ingreso se observó que los pacientes con alto APACHE II tuvieron PCR más altas sin superar $15 \mathrm{mg} / \mathrm{dl}$ (Tabla 3). El tiempo de evolución del dolor en horas presentó una mediana de 24 horas (RIQ 14 a 72 horas). El valor promedio de la PCR al ingreso fue de $7.19 \mathrm{mg} / \mathrm{dl}$ (DE 7.9) (Tabla 4).

El tiempo promedio de ayuno en horas desde el ingreso hasta el inicio de la VO fue de 143.3 (6 días) (DE 80.9). La estancia promedio fue de 7.1 días (DE 3.58) (Tabla 4). La cifra de la PCR al inicio de la VO mostró una media de $4.5 \mathrm{mg} / \mathrm{dl}$ (DE 5.5) (Tabla 4).

Tiempo de evolución y valor de PCR: la mayoría de los pacientes se encontraban en las primeras 24 horas de dolor y de éstos la mayor parte tuvo al ingreso una PCR entre 1.1 y 5 mg/dl (Tabla 5). El 19,7\% requirió nutrición enteral con sonda avanzada (Tabla 1). A ningún paciente se le suspendió la VO una vez reiniciada. El aumento de severidad se presentó en $12,8 \%$ en comparación con $87,2 \%$ que permanecieron con pancreatitis leve (Tabla 1). Las comorbilidades no fueron frecuentes (19\%): la hipertensión arterial con $10 \%$ seguida de infecciones $4 \%$, diabetes mellitus $3 \%$ y cáncer $2 \%$ (Tabla 1). Las complicaciones tempranas y tardías se presentaron en el siguiente orden: necrosis $3,42 \%$, colecciones $2,56 \%$, necrosis infectada y absceso $0,85 \%$ cada una. La mortalidad fue $2,56 \%$ (Tabla 1).
Tabla I. Características de la población

\begin{tabular}{|c|c|c|}
\hline Característica & $n=117$ & (\%) \\
\hline \multicolumn{3}{|l|}{ Severidad } \\
\hline Leve & 117 & 66 \\
\hline Severa & 60 & 34 \\
\hline \multicolumn{3}{|l|}{ Género } \\
\hline Femenino & 43 & 36.8 \\
\hline Masculino & 74 & 63.2 \\
\hline \multicolumn{3}{|l|}{ Edad (años) } \\
\hline $16-20$ años & 5 & 4.3 \\
\hline $21-30$ años & 35 & 29.9 \\
\hline 31 - 40 años & 20 & 17.1 \\
\hline 41 - 50 años & 25 & 21.4 \\
\hline $51-60$ años & 30 & 25.6 \\
\hline$>61$ años & 2 & 1.7 \\
\hline \multicolumn{3}{|l|}{ Etiología } \\
\hline Biliar & 66 & 56.4 \\
\hline Alcohólica & 12 & 10.3 \\
\hline Otra & 39 & 33.3 \\
\hline Idiopática & 27 & 23 \\
\hline PostCPRE & 8 & 7 \\
\hline Medicamentosa & 2 & 1.8 \\
\hline Obstrucción por áscaris & 1 & 0.9 \\
\hline Viral & I & 0.9 \\
\hline \multicolumn{3}{|l|}{ Tipo } \\
\hline Aguda & 103 & 88 \\
\hline Crónica & 14 & 12 \\
\hline \multicolumn{3}{|l|}{ APACHE II ingreso } \\
\hline 0 & 4 & 3.4 \\
\hline 1 & 14 & 12 \\
\hline 2 & 11 & 9.4 \\
\hline 3 & 12 & 10.3 \\
\hline 4 & 18 & 15.4 \\
\hline 5 & 24 & 20.5 \\
\hline 6 & 19 & 16.2 \\
\hline 7 & 15 & 12.8 \\
\hline \multicolumn{3}{|l|}{ Aumento de la severidad } \\
\hline Sí & 15 & 12.82 \\
\hline No & 102 & 87.18 \\
\hline \multicolumn{3}{|l|}{ Comorbilidades } \\
\hline Ninguna & 98 & 81 \\
\hline Cáncer & 2 & 1.7 \\
\hline Diabetes Mellitus & 3 & 2.5 \\
\hline HTA & 12 & 9.9 \\
\hline Infecciones & 6 & 5 \\
\hline \multicolumn{3}{|c|}{ Nutrición enteral por sonda } \\
\hline Sí & 23 & 19.7 \\
\hline No & 94 & 80.3 \\
\hline \multicolumn{3}{|l|}{ Mortalidad } \\
\hline Sí & 3 & 2.6 \\
\hline No & 114 & 97.4 \\
\hline
\end{tabular}

CPRE: colangiopancreatografía retrograda endoscópica; APACHE: acute physiology and chronic health evaluation. 
Tabla 2. Relación entre etiología y género

\begin{tabular}{|l|c|c|}
\hline Género & Femenino & Masculino \\
\hline Etiología & & \\
Biliar & 14 & 52 \\
Alcohólica & 12 & 0 \\
Otras & 17 & 23 \\
\hline
\end{tabular}

Tabla 3. Relación entre PCR y APACHE II al ingreso

\begin{tabular}{|l|c|c|c|c|}
\hline $\begin{array}{l}\text { PCR al ingreso } \\
\text { Apache al ingreso }\end{array}$ & $<$ I & I.I-5 & $5.1-15$ & $>$ I5 \\
\hline 0 & 2 & 0 & 1 & 0 \\
1 & 2 & 5 & 1 & 2 \\
2 & 3 & 3 & 0 & 1 \\
3 & 3 & 4 & 1 & 1 \\
4 & 1 & 5 & 3 & 1 \\
5 & 0 & 6 & 5 & 5 \\
6 & 4 & 3 & 5 & 1 \\
7 & 0 & 5 & 7 & 2 \\
\hline
\end{tabular}

PCR:proteína C reactiva;APACHE II: acute physiology and chronic health evaluation.

\section{Discusión}

En el Hospital de San José la pancreatitis aguda leve corresponde al $66 \%$ y la forma severa al $34 \%$, a diferencia de lo reportado en otros estudios, lo que podría explicarse por el alto nivel de complejidad de nuestra institución y la experiencia en el manejo de la patología biliar.

Es más común en mujeres en la tercera década de la vida y su etiología principal es biliar. La segunda frecuencia es la denominada idiopática porque al no hallar litiasis biliar ni otra causa aparente se solicita ultrasonografía endoscópica para ser valorada por consulta externa, momento en el que se pierde el seguimiento de algunos pacientes y la etiología queda sin esclarecer; la pancreatitis secundaria a ingesta de alcohol es predominante en hombres jóvenes. La secundaria a realización de colangiopancreatografía retrógrada corresponde a un $7 \%$, valor importante teniendo en cuenta que se trata de una complicación del procedimiento. Por último, encontramos casos no comunes como las secundarias a medicamentos, viral y obstrucción por áscaris. La

\begin{tabular}{|l|c|c|cc|}
\hline \multicolumn{5}{|c|}{ Tabla 4. } \\
\hline Variable & Media & DE & $\begin{array}{c}\text { Valor } \\
\text { minimo máximo }\end{array}$ \\
& & & 16 & 70 \\
Edad & 40.38 & 13.4 & 16 & 0 \\
PCR al ingreso & 7.1 & 7.7 & 0.4 \\
PCR al inicio de vía oral & 4.5 & 5.5 & 0 & 28 \\
Horas de ayuno & 162 & 81 & 0 & 384 \\
Estancia hospitalaria (dias) & 7.1 & 3.6 & 2 & 22 \\
\hline
\end{tabular}

Tabla 5. Relación entre tiempo de evolución y PCR

\begin{tabular}{|l|c|c|c|c|}
\hline $\begin{array}{l}\text { Tiempo de evolución } \\
\text { Valor de PCR al } \\
\text { ingreso }\end{array}$ & 24horas & 25 -48horas & 49 -96horas & >\%6horas \\
\hline$<1$ & 15 & 1 & 4 & 1 \\
$1.1-5$ & 24 & 8 & 11 & 1 \\
$5.1-15$ & 17 & 2 & 6 & 3 \\
$>15.1$ & 13 & 7 & 2 & 2 \\
\hline
\end{tabular}

relación de la etiología con el género muestra que la causa biliar se ve más frecuente en mujeres y la alcohólica en hombres, en los otros tipos de pancreatitis no hay ninguna relación evidente. El tiempo promedio de evolución del dolor fue 24 horas sin que el rango sea muy alto ya que oscila entre 12 horas y 3 días y al sobrepasar este tiempo no es útil el valor de la PCR. El APACHE II más frecuente fue 5 y la PCR sube al aumentar este, sin que supere $15 \mathrm{mg} / \mathrm{dl}$. Podría deberse a mayor respuesta inflamatoria y compromiso sistémico. La PCR promedio al ingreso fue $7.19 \mathrm{mg} / \mathrm{dl}$ en contraste con el promedio al inicio de la VO (4.46 $\mathrm{mg} / \mathrm{dl})$. No hubo fracaso en el inicio de la $\mathrm{VO}$ en ningún paciente y a la mayoría se les reinició con valores inferiores de la PCR que los de ingreso.

Los pacientes permanecieron en promedio seis días en ayuno, mientras en otras series fue de 72 horas. ${ }^{5}$ Como se trata de una enfermedad muy catabólica, conviene pensar en modificar los criterios de inicio de la VO y realizar una valoración nutricional al ingreso, durante la hospitalización y el egreso para reconsiderar si se re- 
quiere mayor agresividad con la nutrición enteral por sonda y mayor objetividad en los criterios que determinan el reinicio de la VO.

Algunos estudios consideran que en casos leves el inicio de la nutrición debe ser por VO. ${ }^{3}$ En nuestro estudio fue necesario el empleo de sonda avanzada en 19\%, debido a la demora en la resolución de los síntomas y en la disminución de valores de la PCR, sin que esto significara una progresión en la severidad ni complicaciones. El $12 \%$ de los pacientes presentaron deterioro con paso a grado severo que implicó cambios en el tratamiento requiriendo mayor agresividad y soporte, lo que se relaciona en forma directa con el aumento en el porcentaje de mortalidad.

El $81 \%$ de los que estaban en la tercera década de la vida no presentaron asociación con otras patologías como hipertensión arterial, diabetes mellitus o cáncer. El resto cursó con hipertensión en 10\%, infecciones $4 \%$, diabetes mellitus $3 \%$ y cáncer $2 \%$. En los casos leves las complicaciones son menores; sin embargo, vimos necrosis en $3,42 \%$, colecciones $2,56 \%$, necrosis infectada y absceso $0,85 \%$. No se observaron otras posibles complicaciones tempranas ni tardías. La mortalidad es similar a la presentada en otras series con un porcentaje de $2,56 \%$.

En este estudio encontramos dos limitantes importantes; una es la falta de algunas historias clínicas en el archivo (27 de 247) y otra que el objetivo inicial no se consiguió dado que en las historias revisadas a ningún paciente se le suspendió la VO. Los hallazgos descritos nos aportan información importante en varios aspectos:

1. Se estableció que la pancreatitis leve en el Hospital de San José es menor que la severa como lo informa la literatura, lo que cambia tanto las estadísticas de morbilidad y mortalidad como los manejos. Nuestros casos leves son más jóvenes (21 a 30 años), lo que disminuye las comorbilidades y de esta manera las complicaciones asociadas. Como dato nuevo se conoció que el porcentaje de la forma leve que progresa a severa es de $13 \%$

2. Los casos leves duran mayor tiempo en ayuno en comparación con lo publicado y el $20 \%$ requirió nutrición enteral por sonda, lo cual sugiere revaluar el soporte nutricional actual y los protocolos de manejo.
3. Un resultado importante fue conocer el valor promedio de la PCR para el inicio de la VO (4.46 mg/dl), que servirá para realizar un estudio prospectivo experimental que permita determinar el papel de este marcador de la fase aguda en el inicio de VO y respaldar en forma objetiva su uso rutinario.

\section{Referencias}

1. Famularo G, Minisola G, De Simone C. Clinical practice. Acute pancreatitis. N Engl J Med. 2006; 354(20): 2 142-50.

2. Gurusamy KS, Farouk M, Tweedie JH. guidelines for the management of acute pancreatitis. 2005;54(9): 1344-5.

3. Lankisch PG. Treatment of Acute pancreatitis: an attempted historical review. pancreatology. 2010; 10(2-3): 134-41.

4. Pezzilli R, Uomo G, Zerbi A, Gabbrielli A, Frulloni L, De RP, et al. Diagnosis and treatment of acute pancreatitis: the position statement of the Italian Association for the study of the pancreas. Dig Liver Dis. 2008; 40(10):803-8

5. Papapietro K, Marin M, Diaz E, Watkins G, Berger Z, Rappoport J. [Digestive refeeding in acute pancreatitis. When and how?]. Rev Med Chil. 2001; 129(4): 391-6.

6. Pandey SK, Ahuja V, Joshi YK, Sharma MP. A randomized trial of oral refeeding compared withjejunal tube refeeding in acute pancreatitis. Indian J Gastroenterol. 2004; 23(2): 53-5.

7. Jacobson BC, Vander Vliet MB, Hughes MD, Maurer R, McManus K, Banks PA. A prospective, randomized trial of clear liquids versus low-fat solid diet as the initial meal in mild acute pancreatitis. Clin Gastroenterol Hepatol. 2007; 5(8):946-51.

8. Chebli JM, Gaburri PD, De SouzaAF, Junior EV, Gaburri AK, Felga GE, et al. Oral refeeding in patients with mild acute pancreatitis: prevalence and risk factors of relapsing abdominal pain. J Gastroenterol Hepatol. 2005; 20(9): 1385-9.

9. Meier R, Ockenga J, Pertkiewicz M, Pap A, Milinic N, Macfie J, et al. ESPEN Guidelines on Enteral Nutrition: Pancreas. Clin Nutr. 2006; 25(2): 275-84.

10. Petrov MS, van Santvoort HC, Besselink MG, Cirkel GA, Brink MA, Gooszen HG. Oral refeeding after onset of acute pancreatitis: a review of literature. Am J Gastroenterol. 2007; 102(9): 2079-84.

11. Makola D, Krenitsky J, Parrish CR. Enteral feeding in acute and chronic pancreatitis. Gastrointest Endosc Clin N Am. 2007;17(4): 747-64.

12. Takeda K, Takada T, Kawarada Y, Hirata K, Mayumi T, Yoshida M, et al. JPNGuidelines for the management of acutepancreatitis: medical management of acute pancreatitis. J Hepatobiliary Pancreat Surg. 2006; 13(1):42-7.

13. Levy P, Heresbach D, Pariente EA, Boruchowicz A, Delcenserie R, Millat B, et al. Frequency and risk factors of recurrent pain during refeeding in patients with acute pancreatitis: a multivariate multicentre prospective study of 116 patients. Gut. 1997; 40(2): 262-6.

14. Thomson A. Nutritional support in acute pancreatitis. Curr Opin Clin Nutr Metab Care. 2008; 11(3): 261-6. 